\title{
Characteristic Analysis of Ambient Air Pollutants during Summer Season in Shenyang City
}

\author{
Cheng Liu, Zhonghu Yuan, Yingkui Du*, Chunhe Shi, Yutong Gao, Xiaoxuan Qi, Nan Wang, and Xiaowei Han \\ Shenyang University, School of Information Engineering, Key Lab of Equipment Manufacturing Comprehensive Automation, \\ 110044 Shenyang, China
}

\begin{abstract}
Shenyang City was the political, economic and cultural centre of the northeast China and was also a heavily polluted industrial city. The understanding of the distribution characteristics of air pollutants concentration and changes was still lacked. To reduce the impact of disturbing factors such as firecrackers in the traditional Chinese festivals, the observation period of the monitoring data was selected from $17^{\text {th }}$ May to $21^{\text {st }}$ July in 2016. The data sources were picked from eight national monitoring stations and the daily average concentration of the main air pollutants that included $\mathrm{PM}_{2.5}, \mathrm{PM}_{10}, \mathrm{SO}_{2}, \mathrm{NO}_{2}$ and $\mathrm{O}_{3}$. The overall analysis of distribution characteristics of the air pollutant was shown that the principal pollutants with highest frequency were $\mathrm{O}_{3}$ and $\mathrm{PM}_{10}$, the average proportion was $74.1 \%$ and $20.8 \%$ respectively.
\end{abstract}

\section{Page layout}

Shenyang was a representative manufacturing industrial city with industry with heavy air pollution. The city was the political, economic and cultural center of the northeastern China and was located in the heart of the Northeast Asian economic circle and the Bohai Sea economic circle.

Shenyang City located in central region of Liaoning Province. The terrain was mainly consisted of flat plain. The average altitude was about 50 meters and the east region was lower than the west. The north of Shenyang City was close to the south Horqin desert of the Inner Mongolia Autonomous Province and was threatened by sandstorm. Shenyang belongs to the northern temperate monsoon-influenced semi-humid continental climate.

The industry of Shenyang City was mainly included the traditional heavy industry such as coal, metallurgy, power, chemical and machinery manufacturing. With the process of urbanization and the rapid economic development, serious environmental problems especially the compound air pollution were arisen ${ }^{[1]}$. As the Shenyang Environmental Status communique in 2014 ${ }^{[2]}$ shown, the annual concentration of $\mathrm{PM}_{10}$ and $\mathrm{PM}_{2.5}$ has reached $124 \mu \mathrm{g} / \mathrm{m}^{3}$ and $74 \mu \mathrm{g} / \mathrm{m}^{3}$ respectively that were the 3.1 and 4.9 times of the Chinese ambient air quality standard respectively. The annual good quality air quality was only 191 days. The atmospheric environment qualities of Shenyang City were ranked the last $15^{\text {th }}$ and the last $11^{\text {th }}$ during the 74 key cities in 2013 and 2014 years.
The understanding of the distribution characteristics of air pollutant concentration and changes was still lacked ${ }^{[1,7]}$. This main contribution was to analyze the characteristics of primary air pollutions of the $\mathrm{PM}_{2.5}$, $\mathrm{PM}_{10}, \mathrm{SO}_{2}, \mathrm{NO}_{2}$ and $\mathrm{O}_{3}$ during summer season in Shenyang that was driven by the data of daily average concentration released by Shenyang environmental monitoring stations.

\section{Data and methods}

The data referred to in this paper were the monitoring data of air pollution during the heating season of 8 Shenyang environmental air quality monitoring stations. The time period was from 17 May to 21 July in 2016, 65 days total.

The data mainly include the daily average concentrations of $\mathrm{PM}_{2.5}, \mathrm{PM}_{10}, \mathrm{SO}_{2}, \mathrm{NO}_{2}$ and $\mathrm{O}_{3}$ of the eight national monitoring stations which were released by Dongling Road, Jing Shen Street, Xiaoheyan Road, Culture Road, Xinxiu Street, Hunnan East Road, Lingdong Street and Taiyuan Street.

The R language was selected as the tool to realize the analysis and graphing the results. The obvious advantages of the $\mathrm{R}$ language were that it was open source and free with Built-in utility function with a large number of dedicated for statisticians.

Statistical methods were utilized for the analysis of the contribution characteristics of ambient air pollution. The occurrence proportion was defined as the proportion of the number of days of air pollutant occurred in the total number of days of the sample data to evaluate the occurrence frequency of the primary air pollutions. The 
distribution characteristics of the main air pollutants were plotted and shown by the boxplot tools of the $\mathrm{R}$ language.

\section{Results and discussion}

\subsection{Overall distribution characteristics}

The daily average concentrations of $\mathrm{PM}_{2.5}, \mathrm{PM}_{10}, \mathrm{SO}_{2}$, $\mathrm{NO}_{2}$ and $\mathrm{O}_{3}$ air pollutants in Shenyang summer period were shown in Fig 1. The proportions of the number of days of the primary air pollutants occurred in the total number of days were calculated at the beginning and the distribution of the main pollutants as the primary pollutant was analyzed.
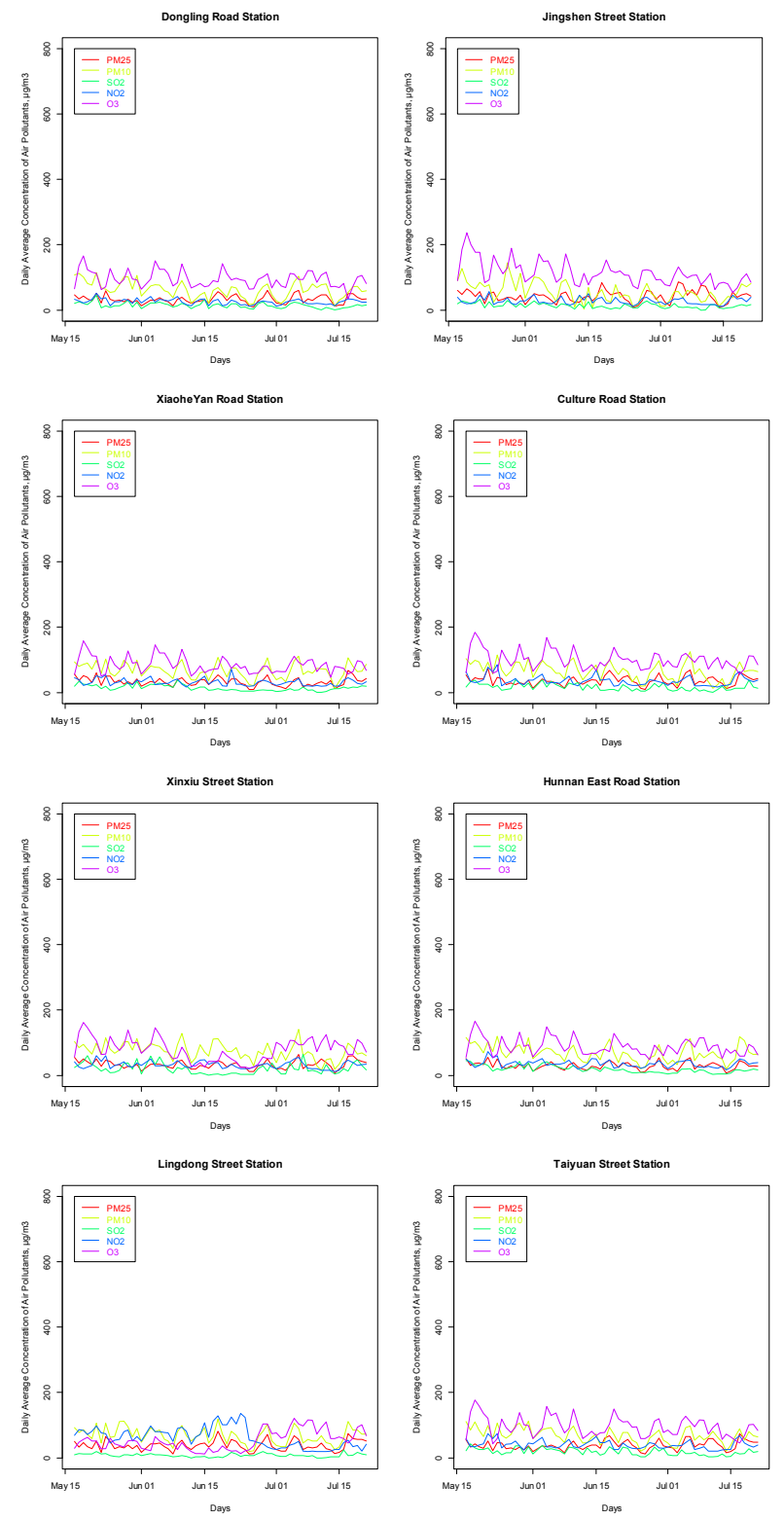

Fig. 1. Daily average concentration of pollutants during summer season

For the quantitative analysis that was shown in Table.1, the proportion of the number of days of occurrence of primary air pollutants includes two types: the independent proportion of each monitoring point and the average proportion. The principal pollutants with highest frequency were $\mathrm{O}_{3}$ and $\mathrm{PM}_{10}$, the average proportion was $74.1 \%$ and $20.8 \%$ respectively. The number of days that $\mathrm{O}_{3}$ appears as the primary pollutant were $58,63,49,57,31,51,22$ and 57respectively, and the proportions were $89.3 \%, 95.5 \%, 74.2 \%, 87.8 \%$, $48.4 \%, 78.5 \%, 32.9 \%$ and $86.4 \%$ respectively, the mean was $74.1 \%$.

The $\mathrm{PM}_{10}$ was the $2^{\text {nd }}$ pollutant in the sample data of 8 national monitoring stations The number of days was 7 , $2,17,7,34,14,20$ and 9, the proportion was $10.7 \%$, $3.0 \%, 25.8 \%, 10.7 \%, 51.6 \%, 21.5 \%, 29.8 \%$ and $13.6 \%$ respectively.

Table 3. The total proportion of the primary air pollutant

\begin{tabular}{|c|c|c|c|c|c|c|c|c|c|c|}
\hline \multirow{2}{*}{ Station } & \multicolumn{2}{|c|}{$\mathrm{PM}_{2.5}$} & \multicolumn{2}{|c|}{$\mathrm{PM}_{10}$} & \multicolumn{2}{|c|}{$\mathrm{SO}_{2}$} & \multicolumn{2}{|c|}{$\mathrm{NO}_{2}$} & \multicolumn{2}{|c|}{$\mathrm{O}_{3}$} \\
\hline & $\mathrm{D}$ & $\mathrm{P}$ & $\mathrm{D}$ & $\mathrm{P}$ & D & $\mathrm{P}$ & $\mathrm{D}$ & $\mathrm{P}$ & $\mathrm{D}$ & $\mathrm{P}$ \\
\hline $\begin{array}{c}\text { Donglin } \\
\mathrm{g} \text { Road }\end{array}$ & - - & - & 7 & $10.7 \%$ & - & - & - - & - & 58 & $89.3 \%$ \\
\hline $\begin{array}{c}\text { Jingshen } \\
\text { Street }\end{array}$ & 1 & $1.5 \%$ & 2 & $3.0 \%$ & - & - & - - & -- & 63 & $95.5 \%$ \\
\hline $\begin{array}{l}\text { Xiaohey } \\
\text { an Road }\end{array}$ & - & - & 17 & $25.8 \%$ & - & - & - & -- & 49 & $74.2 \%$ \\
\hline $\begin{array}{c}\text { Culture } \\
\text { Road }\end{array}$ & - - & - - & 7 & $10.7 \%$ & - - & - - & 1 & $1.5 \%$ & 57 & $87.8 \%$ \\
\hline $\begin{array}{c}\text { Xinxiu } \\
\text { Street } \\
\end{array}$ & - & - & 34 & $51.6 \%$ & - & - & - - & -- & 31 & $48.4 \%$ \\
\hline $\begin{array}{c}\text { Hunnan } \\
\text { East } \\
\text { Road }\end{array}$ & -— & - - & 14 & $21.5 \%$ & - & - & - & -- & 51 & $78.5 \%$ \\
\hline $\begin{array}{c}\text { Lingdon } \\
\text { g Street }\end{array}$ & - & - & 20 & $29.8 \%$ & - & - - & 25 & $37.3 \%$ & 22 & $32.9 \%$ \\
\hline $\begin{array}{c}\text { Taiyuan } \\
\text { Street }\end{array}$ & - & - & 9 & $13.6 \%$ & - & - - & - - & - & 57 & $86.4 \%$ \\
\hline
\end{tabular}

*The $\mathrm{D}$ denotes the total number of days; the $\mathrm{P}$ denotes the proportion of each pollutant occurred.

According to the above analysis, it can be seen that the $\mathrm{O}_{3}$ was the most important air pollutant with the highest occurrence proportion during the summer season. According to the average proportion of the main air pollutants as the primary pollutants, the $\mathrm{PM}_{10}$ Particle matter was ranked as the second one.

It was necessary to carry out special case that the average daily concentration of $\mathrm{NO}_{2}$ as the primary pollutant during the summer season was 25 days in the data of Lingdong Street national monitoring station.

\subsection{Fluctuation characteristics of main air pollutants}

As shown in Fig 2, the fluctuation characteristics of the main air pollutants was displayed and analyzed using the box diagram method. The $\mathrm{PM}_{2.5}, \mathrm{PM}_{10}, \mathrm{SO}_{2}$ and $\mathrm{NO}_{2}$ fluctuation characteristics were regular and stable.

From the Fig 2, it was obviously can be seen that the region that nearby the road with larger traffic flow was with the lower fluctuation of the daily average concentration of $\mathrm{O}_{3}$, such as the stations of the Jing Shen Street, Culture Road, Hunnan East Road and Taiyuan Street. On the contrary, lower traffic flow was corresponding to higher concentration in the regions of Dongling Road, Xiaoheyan road, Xinxiu Street and 
Lingdong Street. As were shown in Table 2. To understanding the characteristics of the spatial distribution, the comparative analysis of the data of the 8 national stations will be done.
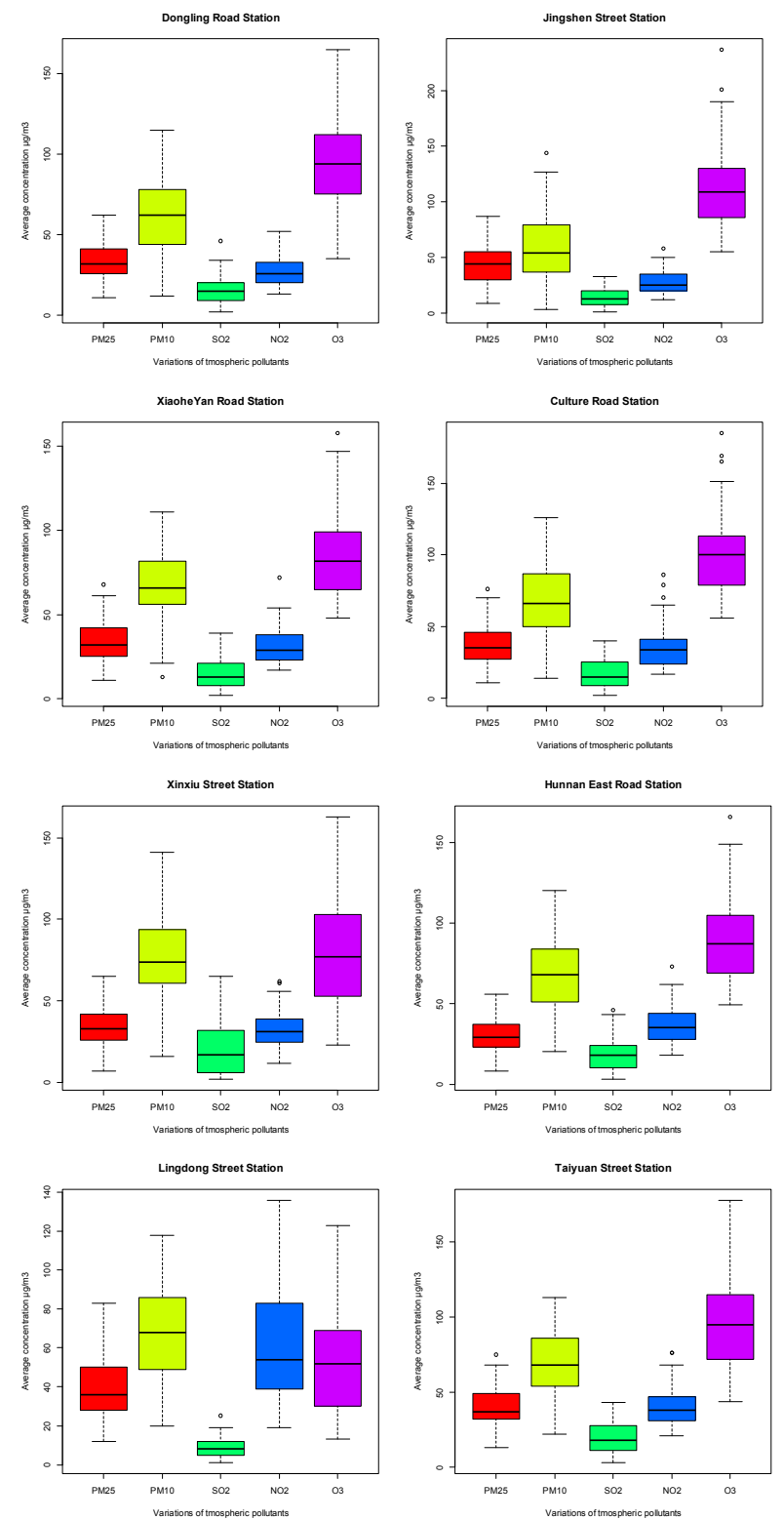

Fig. 2. Fluctuation characteristics of major air pollutants

Table 2. The statistical analysis in boxplots

\begin{tabular}{l|l|l|l|l|l|l|l|l}
\hline & $\begin{array}{l}\text { Dong } \\
\text { ling } \\
\text { Road }\end{array}$ & $\begin{array}{l}\text { Jing } \\
\text { shen } \\
\text { Street }\end{array}$ & $\begin{array}{l}\text { Xiao } \\
\text { heyan } \\
\text { Road }\end{array}$ & $\begin{array}{l}\text { Culture } \\
\text { Road }\end{array}$ & $\begin{array}{l}\text { Xin } \\
\text { xiu } \\
\text { Street }\end{array}$ & $\begin{array}{l}\text { Hunnan } \\
\text { East } \\
\text { Road }\end{array}$ & $\begin{array}{l}\text { Ling } \\
\text { dong } \\
\text { Street }\end{array}$ & $\begin{array}{l}\text { Tai } \\
\text { yuan } \\
\text { Street }\end{array}$ \\
\hline 1st Qu & 75 & 86 & 65 & 79 & 53 & 69 & 30 & 72 \\
\hline Median & 94 & 109 & 82 & 100 & 77 & 87 & 52 & 95 \\
\hline 3rd Qu 112 & 130 & 99 & 113 & 103 & 105 & 69 & 115 \\
\hline
\end{tabular}

\subsection{Locations of the monitoring Station and corresponding urban areas}

The locations of the 8 national monitoring stations involved in this paper and the corresponding urban area were shown in Table 3. The geographical location of each urban area was different, so its air pollution sources were largely different inevitably.

According to the results of the data analysis, the urban areas were divided into two types by the traffic flow that were denoted as the relative larger traffic flow urban area and the relative lower traffic flow urban area. The two types of urban area were referred to as larger flow area and lower flow area.

Table 3. The classification of urban corresponding to different monitoring station

\begin{tabular}{l|l|l}
\hline Station & Urban Area & Location \\
\hline Dongling Road & $\begin{array}{l}\text { Qipanshan Development } \\
\text { Dwastrict }\end{array}$ & $3^{\text {rd }}$ cyclic \\
\hline Jing Shen Street & Shenbei New Dwastrict & $3^{\text {rd } c y c l i c ~}$ \\
\hline Xiaoheyan road & Dadong Dwastrict & $1^{\text {st }}$ cyclic \\
\hline Culture Road & Heping Dwastrict & $1^{\text {st }}$ cyclic \\
\hline Xinxiu Street & Hunnan New Dwastrict & $3^{\text {rd }}$ cyclic \\
\hline Hunnan East Road & Hunnan New Dwastrict & $3^{\text {rd }}$ cyclic \\
\hline Lingdong Street & Huanggu Dwastrict & $1^{\text {st }}$ cyclic \\
\hline Taiyuan Street & Heping Dwastrict & $1^{\text {st }}$ cyclic \\
\hline
\end{tabular}

\subsection{Distribution characteristics of $\mathrm{O}_{3}$ pollutant}

As were shown in Table 4, the maximal daily average concentration of $\mathrm{O}_{3}$ was $237 \mu \mathrm{g} / \mathrm{m}^{3}$ in Jing Shen Street station, the minimum daily average concentration was $13 \mu \mathrm{g} / \mathrm{m}^{3}$ in Lingdong Street station.

The maximal mean value of the daily average concentration of $\mathrm{O}_{3}$ was $114.8 \mu \mathrm{g} / \mathrm{m}^{3}$ in Jing Shen Street station, the minimum mean value was $54.6 \mu \mathrm{g} / \mathrm{m}^{3}$ in Lingdong Street station. The mean value of the daily average concentration of $\mathrm{O}_{3}$ in Jing Shen Street station was twice more than the mean value of Lingdong Street site.

Table 4. Primary air pollution distribution of the core area

\begin{tabular}{l|l|l|l}
\hline \multirow{2}{*}{$\begin{array}{l}\text { National Monitoring } \\
\text { Station }\end{array}$} & \multicolumn{3}{|c}{ Daily Average Concentration of $\mathbf{O}_{\mathbf{3}}$} \\
\cline { 2 - 4 } & Max & Mean & Min \\
\hline Dongling Road & 165 & 96 & 35 \\
\hline Jing Shen Street & 237 & 114.8 & 55 \\
\hline Xiaoheyan road & 158 & 85.6 & 48 \\
\hline Culture Road & 185 & 101.3 & 56 \\
\hline Xinxiu Street & 163 & 80.3 & 23 \\
\hline Hunnan East Road & 166 & 89.9 & 49 \\
\hline Lingdong Street & 123 & 54.6 & 13 \\
\hline
\end{tabular}

From the Table 4, it was obviously can be seen that the larger flow area was with the higher daily average concentration of $\mathrm{O}_{3}$, such as the national monitoring stations of the Jing Shen Street, Culture Road, Hunnan East Road and Taiyuan Street. 
On the contrary, lower flow area corresponding to the lower concentration. This type regions include Dongling Road, Xiaoheyan road, Xinxiu Street and Lingdong Street.

The mean value of the mean daily average concentration of $\mathrm{O}_{3}$ in larger traffic flow region was $100.7 \mu \mathrm{g} / \mathrm{m}^{3}$ and the mean value of the lower traffic flow region was $79.1 \mu \mathrm{g} / \mathrm{m}^{3}$, which was lower about $21.4 \%$.

\section{Summary}

The distribution characteristics of the major air pollutions in Shenyang City during the summer season were analyzed from different aspects. The overall analyzes of distribution characteristics of the air pollutant was shown that the principal pollutants with highest frequency were $\mathrm{O}_{3}$ and $\mathrm{PM}_{10}$. The mean proportion was $74.1 \%$ and $20.8 \%$ respectively. The regions that nearby the road with larger traffic flow can be confirmed with the lower fluctuation of the average concentration of $\mathrm{O}_{3}$. It has active significance for the government decision making by providing necessary scientific basis and data support.

\section{Acknowledgment}

This work was supported by Science and Technology Program of Shenyang City (F16-155-9-00, 17-180-9-00) and Science and enterprise competitive selection project of Shenyang City (Study on the risk management and remediation technology of urban ecological environment).

\section{References}

1. Qiu Weiguang, Zhang Qingxin, Chen Zongjiao, $\mathrm{Zu}$ Biao, Tai Shanshan, Bai Lu, Zhang Xiaofeng. Characteristics and Cause Analysis of One Typical Air Pollution in the Winter of Shenyang City. Environmental Protection Science, 2016, 42(4) : 106-109.

2. http://www.shenyang.gov.cn/zwgk/system/2015/05/ 26/010114621.shtml.

3. Jiang, J., Zhou, W., Cheng, Z., Wang, S., He, K., \& Hao, J. Particulate matter distributions in China during a winter period with frequent pollution episodes. Aerosol Air Qual. Res, 15(2): 494-503.

4. Zhang J, Zhu T, Kipen H, et al. Cardiorespiratory biomarker responses in healthy young adults to drastic air quality changes surrounding the 2008 Beijing Olympics. Research Report, 2013, pp:5-174.

5. Zhang X Y, Wang Y Q, Niu T, et al. Atmospheric aerosol compositions in China: spatial/temporal variability, chemical signature, regional haze distribution and comparisons with global aerosols. Atmospheric Chemistry and Physics, 2012, 12(2): 779-799.

6. Yan Wenlian, Zhou Deping, Wang Yangfeng, et al.Studies on the Concentration and Scale
Distribution of Inhalable Particulate Matter in Shenyang and Winter. Journal of Applied Meteorology, 2008, 19 (4): 435-442. 